\title{
Ovarian Cystadenocarcinoma
}

National Cancer Institute

\section{Source}

National Cancer Institute. Ovarian Cystadenocarcinoma. NCI Thesaurus. Code C5228.

An adenocarcinoma that arises from the ovary and is characterized by the presence of

cystic structures. It includes the serous cystadenocarcinoma, mucinous

cystadenocarcinoma, and clear cell cystadenocarcinoma. 